\title{
La evolución de la imagen literaria del paisaje urbano: de la ciudad moderna a la ciudad actual
}

\section{The evolution of the literary image of the urban landscape: from the modern city to the city today}

\author{
Félix Pillet Capdepón*
}

\section{INTRODUCCIÓN}

La relación Geografía y Literatura se conformó con el estudio de la imagen literaria del paisaje, logrando su culminación en España con la generación del 98, que convirtió el paisaje castellano en «un verdadero paisaje nacional» (Ortega, 2007 y 2010: 49); sin olvidar el «absoluto predominio de la observación» y el paisajismo geográfico que aportaron, respectivamente, los libros de viajes de ilustrados y románticos (López Ontiveros, 2006: 28), narraciones retrospectivas a las que se unieron guías de viajes «de intención mucho más modesta y aplicada» (Arroyo, 2008: 418), todo ello como resultado de un ejercicio de sabiduría, de saber mirar el paisaje (Martínez de Pisón, 2009).

Los estudios geográficos sobre el paisaje urbano durante los últimos años han sido escasos, parece oportuno que en el llamado «siglo de las ciudades», recordemos algunas propuestas, como la realizada por Capel (2001: 146-147) en la que demuestra la perfecta conexión con la literatura, a través de la obra de Borges, señalando que la ciudad es «ese producto excelso de la cultura». Otro geógrafo, Bertrand Lévy (2006: 472) indicaba que los grandes literatos

* Universidad de Castilla-La Mancha. Departamento de Geografía y Ordenación del Territorio (Campus de Ciudad Real). 
siempre tuvieron necesidad de la ciudad, de algunas ciudades, para ubicar su acción y alimentar sus reflexiones, pues ellos nos entregan «un informe explicativo esencial sobre la ciudad». El análisis del proceso de urbanización lo relacionaremos con la obra literaria, como complemento al discurso geográfico y en algunas ocasiones dando prioridad a esta última, con el fin de analizar las principales ciudades españolas, pero también la que ha sido la metrópoli desde comienzos del siglo pasado y hoy ciudad global: Nueva York, ya que ha interesado a diversos escritores españoles. Dicho proceso se ha tratado y sistematizado en distintas obras que nos ayudan a comprender mejor el desarrollo del hecho urbano (Pacione, 2001; Lois, 2012; y Pillet, 2012a). Nuestro objetivo es centrarnos, sin ánimo de ser exclusivos, en la diferenciación entre la ciudad moderna y la actual, a partir de la obra literaria realizada por escritores españoles en lengua castellana, tanto narradores como poetas, con el deseo de detenernos en las que ofrezcan claramente descripción de las ciudades, lo que nos ha obligado a prescindir de un gran número de obras ${ }^{1}$, que no aportaban documentación para el conocimiento de la morfología urbana, sin tener en cuenta, en ningún momento, la trama o el contenido de la obra.

La ciudad se ha convertido en el espacio literario preferido de los escritores, en ella se funden «el mito, la invención y la realidad», de hecho hay autores que han logrado una simbiosis perfecta con su ciudad natal o de adopción (García Jambrina, 2006). Tanto Barcelona como Madrid han sido una constante en el intento de adaptación del texto a la intención urbana, como clave literaria que pretende hacer legible la ciudad (Carrión, 2009). En las últimas décadas se han llevado a cabo varias tesis doctorales que van desde la Guerra Civil hasta la actualidad, sobre espacios urbanos españoles que profundizaron en la relación entre literatura y ciudad: Madrid como escenario literario en la novela española contemporánea escrita por Del Moral (1992), centrada en los años 1939 a 1975; Barcelona: la novel.la urbana (1944-1988) de Sturm-Trigonakis, traducida del alemán (1996), incluyendo obras escritas en castellano y catalán²; La ciudad de las palabras. Imágenes urbanas en novelas españolas contemporáneas de López Cabrales (2000), novela social urbana de los años 1956 a 1976; La configuración de la imagen de la gran ciudad en la literatura postmoderna: (ámbito romántico) de Tutoras (2004) donde se analiza el Madrid de la actual etapa posmoderna; y por último, Dones i ciutat a la Barcelona del segle XX: Una anàlisi geográfica a través de la literatura de Edd (2005), es decir, la ciudad de Barcelona desde una visión de género durante el pasado siglo. El

\footnotetext{
${ }^{1}$ El ejemplo más significativo sería La colmena (1951) de Camilo José Cela, entre otras.

2 Citada por Schwarzbürger (2002: 208-209).
} 
propio López Cabrales (2000) afirma que aunque existen obras donde apenas se menciona el espacio urbano de referencia, por el contrario en otros textos la ciudad aparece descrita «con un lujo de detalles que proporcionan interesantes noticias para posibles análisis e interpretaciones urbanísticas». No cabe duda, como así se ha demostrado, que la novela, en sustitución de los libros de viajeros, cada vez menos frecuentes, se presta mejor que ningún otro género para elaborar el tema de la ciudad, aunque la mayor parte de las veces ésta aparezca más como fondo que como tema.

Junto a la aportación literaria, no podemos olvidar otras fuentes, aunque ahora no las utilicemos, como es el caso de la pintura, los dibujos, la cartografía, las ilustraciones y la fotografía que ayudan a comprender la idea del paisaje urbano (Maderuelo, 2010). Se ha afirmado que la literatura, el grabado y la pintura contribuyen a definir como «culturales» paisajes urbanos que sobresalen por su emplazamiento, entorno, entramado y construcciones (Zárate, 2010: 187). Un buen ejemplo es la obra realista de Antonio López, contemplada como «una visión cálida e intemporal de la ciudad» donde convierte a Madrid en "protagonista de la pintura» tal y como señala el pintor (Espejo y López de los Mozos, 2012: 218 y 222).

\section{LA CIUDAD MODERNA}

El paso de la ciudad preindustrial a la industrial durante el siglo XIX dio lugar, en un primer momento, a una mayor utilización del espacio construido, gracias a los edificios y terrenos aportados dentro y fuera del recinto amurallado por el proceso desamortizador. Con la ciudad industrial, y tras el derrumbe de las murallas y la llegada del ferrocarril y de las industrias, se inician los procesos de ensanche. Esta expansión vino acompañada del rechazo de los habitantes, pues veían en la nueva ciudad el origen de todas las enfermedades y desgracias. La novela moderna pondrá en boca de sus personajes todos los males que estaba sufriendo la población (Muñoz, 2010 y 2012), y especialmente los del 98, pues dieron una visión pesimista, así como las nuevas transformaciones urbanas. No cabe duda que la primera y gran novela de interés geográfico-literario fue, sin duda, La Regenta (1884-85), de Leopoldo Alas «Clarín» donde nos presenta a Vetusta (Oviedo) como una ciudad en transformación. El autor nos ofrece una auténtica anatomía de la sociedad de la Restauración. Muy bien hubiera podido titularse la novela Vetusta pues parece un claro objetivo dar una visión estructurada de su distribución urbana (Pérez, 2006). La obra se inicia con un comienzo eminentemente romántico, al 
que se une un documento de verdadera descripción realista de sus distintas zonas: el centro histórico «la Encimada era el barrio noble y el barrio pobre de Vetusta»; en segundo lugar, el ensanche burgués o nuevo urbanismo planificado, es decir, «la Colonia» o «la Vetusta novísima tirada a cordel»; y por último, la única barriada obrero-industrial.

\section{Madrid y su consolidación como capital}

Mientras unas ciudades se convirtieron en el centro de atención de la transformación urbana, como fue el caso de Madrid y Barcelona, la mayor parte se correspondía con pequeños núcleos urbanos o capitales de provincia enclavadas en el ambiente rural, fuertemente dominados por la sociedad estamental: nobleza y clero, situación que se conoce literariamente como "ciudad levítica» (Langa, 1994). A comienzos del siglo XIX, Madrid, la Villa y Corte, aún era una capital por hacer, las principales transformaciones urbanas vinieron de la mano del proceso desamortizador, ya que se permitió el crecimiento urbano dentro del recinto de la muralla, aprovechando los edificios y los huertos que dejaron de ser regentados por las órdenes religiosas, para pasar a manos de la burguesía y del poder político, lo que posibilitó aprovechar el suelo y los edificios desamortizados para nuevas funciones con el fin de poder dotarla de los equipamientos capitalinos que necesitaba para estar en igualdad de condiciones con otras capitales europeas. Fuera de las murallas se construyeron los primeros cementerios, como solución a uno de los problemas de higiene.

Dos autores costumbristas nos dejaron claro reflejo de las mejoras que se iban experimentando en el proceso de renovación del parque inmobiliario, así como de las deficiencias que ofrecía como capital del Estado, pues en aquellos momentos otras ciudades españolas presentaban mejor presencia. En el recopilatorio Artículos de costumbres de Mariano José de Larra, el mejor cronista de la sociedad del momento, «personaje decisivo de la modernidad española» (Sierra, 2006: 9), se preguntaba sí los cementerios estaban fuera o dentro de las murallas como crítica a la vida urbana de aquellos momentos; en uno de sus textos, Las casas nuevas (1833) informa del rápido proceso de sustitución de inmuebles, dentro de los límites de la muralla, observando la aparición de viviendas de mayor altura, al tiempo que se va sustituyendo la construcción de tipo rural. Cuando se refiere a las casas antiguas señalará «que van desapareciendo en Madrid rapidísimamente», haciendo mención a su irregular morfología interior. Respecto a las de nueva creación indicará que «surgen de la noche a la mañana por todas las calles de Madrid», con más «balcones que la- 
drillos y más pisos que balcones», lo que mostraba la transformación que se estaba operando en las viviendas y especialmente en la morfología de las nuevas fachadas burguesas. Por su parte, Ramón de Mesonero Romanos en sus Escenas Matritenses (1846), nos indica en Paseos por las calles la situación negativa de la ciudad, y su esperanza en un futuro próximo. Señalaba que la capital no posee edificios de gran altura, ni equipamientos como una catedral, desde la que poder ver su panorámica, «a vista de pájaro». Hacía referencia al mal estado de las calles y fachadas, esperando que se hiciera de una forma general el «revoque de las casas».

La caída de la muralla favoreció la expansión urbana y la conexión con el ferrocarril, la población se incrementó con la llegada de inmigrantes de las distintas provincias españolas, ocupando los espacios de la vieja trama, más los nuevos trazados urbanos que se proyectaron, unos rodeando la trama original radioconcéntrica, como fue el Ensanche de Castro (1860), diseñado para asentar a la burguesía y a las clases medias, imprimiendo una cierta segregación social y funcional mediante la correspondiente zonificación de la ciudad. Posteriormente, como proyección periférica e higienista aparecería la Ciudad Lineal de Soria (1882), antecedente de la periurbanización (Lois, 2012: 122). Las primeras manifestaciones literarias se centraron en la trama histórica de la ciudad, en el centro y en los viejos suburbios, Benito Pérez Galdós, en una de sus mejores novelas, Fortunata y Jacinta (1887) nos habla de la sociedad urbana matritense, reconoce que mucho tiene que imitar esta ciudad a «la sin par Sevilla», pues en el fondo Madrid, aunque es grande, sigue siendo «una aldea». Señala que la primera expansión interior se debió a los beneficios de la desamortización debido al aporte de edificios y solares para nuevas funciones «que la desamortización edificara una ciudad nueva sobre los escombros de los conventos». En Misericordia (1897) nos presenta la otra cara de la ciudad, la del suburbio «lleno de montones de basura, residuos, despojos y desperdicios de todo lo humano», lo que demuestra las malas condiciones higiénicas que se soportaban.

Desde comienzos del nuevo siglo se atisba el paso de la sociedad burguesa de corte liberal a la nueva sociedad capitalista. Todo ello da como resultado una postura crítica ante los problemas del país, situación que encontramos en la capital del Estado pero también en Barcelona ${ }^{3}$. El mejor ejemplo de lo afirmado lo representó José Martínez Ruiz «Azorín» con su primera novela La voluntad (1902), escrita en el Madrid más viejo y sórdido, uniendo lo real con lo ficticio,

\footnotetext{
${ }^{3}$ La novela de Dolors Monserdà La Fabricanta (1904), traducida en 1972 (Mcdonogh, 1988).
} 
la literatura con el periodismo, muestra clara de regeneracionismo, activismo ideológico e indagación psicológica. El mejor paisajista de su generación nos mostrará una visión urbana nueva, que demuestra que la naciente gran ciudad no viene a resolver nada pues enerva y favorece su abandono, debido al exceso de ruido y tránsito urbano en las principales vías, en una sociedad que sigue manteniéndose en sus tradiciones: «Hay en el ambiente de estas grandes ciudades, a esta hora, una sensación de voluptuosidad y de fatiga, de serenidad y de enervamiento...». Dentro de esta misma línea de renovación literaria, encontramos a su amigo y compañero de generación Pío Baroja con dos novelas importantes, la primera Camino de perfección (1902) donde el autor expresa de manera radical su rechazo a la ciudad industrial (Madrid) y su interés por las ciudades donde gravita el pasado y se remansa el presente, pues la «gran capital con sus chimeneas era el mostruo», proponiendo, al mismo tiempo, la huida a Toledo, ciudad considerada como mística, como ciudad del pasado o preindustrial. Por otro lado, en su novela La Busca (1904), nos habla del Madrid real, de gentes humildes y bajos fondos, de la sociedad urbana y suburbana, desamparada, abigarrada y violenta. En ella nos ofrece su visión sobre los domingos del Rastro rebosante de gente, de la Ribera de Curtidores y de las zonas próximas al Manzanares «espectáculo de miseria y sordidez, de tristeza e incultura que ofrecen las afueras de Madrid con sus rondas miserables, llenas de polvo en verano y de lodo en invierno». El interés literario por esta zona de Madrid continuó durante la década siguiente, Ramón Gómez de la Serna, ofrece un libro de ensayo titulado El Rastro (1915) en él nos muestra un suburbio donde «la población se va empobreciendo», lleno de gentes y transeúntes que venden y compran un "montón de cosas», en un urbanismo que mezcla casas de ladrillo rojo, con otras que llaman la atención por sus balcones y buhardillas, todo ello en un viario irregular: «hay bocacalles estrechas y empinadas, que se tuercen en recodos que cierran y resguardan más el Rastro», como corresponde a las áreas más degradadas e irregulares de la trama histórica.

Distinta es la visión de Juan Ramón Jiménez en su narración La colina de los chopos: Madrid posible e imposible (1914 y 1920). En ella desvela, inmerso en un conflicto estético y social, la luz y el color de la ciudad. Convierte su obra en una exploración del espacio vivido, unas veces como sensible espectador y otras como crítico implacable de las aberraciones urbanísticas (Rozas, 1996). En su obra nos describe lo que él denomina un «pueblo manchego» que está iniciando su deterioro: «ha perdido el arraigo, la fuerza, con la ausencia total de su armonía natural y su belleza propia. Es una muestra evidente de decadencia total...». 
Estos textos literarios nos ayudan a conocer la transformación de la capital, pero también las diferencias existentes entre las diversas zonas de la ciudad, especialmente los sectores más deteriorados. Tanto Madrid como el resto de las capitales de provincia vieron crecer su población, al tiempo que el campo se vaciaba. Uno de los mayores problemas fue la ausencia de viviendas para la incipiente clase media y para los sustratos de población con menos ingresos, apenas resuelto con la legislación de «casas baratas». Nos centraremos ahora preferentemente en las ciudades castellanas que rodeaban a Madrid y de la que dependían estrechamente.

\section{Capitales de provincia en el tránsito del siglo XIX al Xx}

El aviso de la llegada del ferrocarril a comienzos de la segunda mitad del siglo XIX a las puertas de las ciudades obligaba a preocuparse por su «ornato» por mejorar su presencia, limpiando y encalando sus fachadas, empedrando sus calles, pues ahora iban a estar más expuestas al exterior. Sus murallas comenzaron a caer, no por que representaran un obstáculo al desarrollo suburbano, pues la razón fundamental de dicho derribo parcial se debió a la necesidad de comunicar la trama urbana con la estación de trenes. Las ciudades estaban experimentando un cambio importante en su estructura estamental, la Iglesia había perdido su poder económico como consecuencia del proceso desamortizador, la nobleza local seguía manteniendo sus privilegios, al tiempo que una nueva burguesía integrada por comerciantes, industriales y burócratas, principal beneficiaria de la desamortización, iba escalando los primeros lugares en las listas de mayores contribuyentes. Todo ello acompañado de una escasa riqueza pública o municipal que imposibilitaba llevar a cabo las mínimas mejoras urbanas.

La emigración del campo a la ciudad favoreció a estas capitales de provincia viendo crecer su curva de población de forma considerable, pero su aparente desarrollo social no condicionó un espíritu de modernidad, eran como se les ha denominado en el mundo literario: «ciudad muerta» (Lozano, 1994), principal lugar de refugio para quienes no soportaban el trepidante desarrollo de las grandes ciudades, en este caso Madrid, y por este motivo las eligieran como destino preferente. Arroyo (1989: 362-363) al referirse a los hombres del 98 señala que mostraron cierta aversión ante el hecho urbano, en referencia a la ciudad moderna, destacando en tres de ellos las siguientes aportaciones: la visión crítica de la vida urbana en Azorín, la marginalidad de los barrios en Baroja, y la excepción de Salamanca en Unamuno. Para analizar estas circunstancias nos ha parecido conveniente relacionar tres ciudades caste- 
llanas con los tres autores antes citados: Baroja con Cuenca, Azorín con Segovia y Unamuno, por supuesto, con Salamanca. En ellas se hace mención expresa y detallada a sus diferentes emplazamientos y a los ríos que las rodean. Pío Baroja nos traslada en su obra Los recursos de la astucia (1915) a la ciudad de Cuenca. Destaca la situación estratégica de la urbe, su curioso emplazamiento, con un «aire de centinela y observador», rodeada de barrancos «llamados Las Hoces» donde centra su preocupación por describir los pequeños detalles de la parte alta: «es una pirámide de casas viejas, apiñadas, manchadas por la lepra amarilla de los líquenes», así como su necesaria expansión en la llanura «bajar de su roca a la llanura...creó un arrabal o ciudad baja...». Por su parte, José Martínez Ruiz «Azorín» publicaría su novela Doña Inés (1925), donde la ciudad de Segovia se convierte en protagonista, como resultado de un proceso evolutivo que ha ido acumulando nobles construcciones rodeadas de naturaleza viva y de luminosidad, pues como él señala, «No podemos poner al pronto orden y sosiego en la admiración» de cuanto alcanza ver su mirada. Por último, Miguel de Unamuno, en su libro Andanzas y visiones españolas (1922), este bilbaíno asentado en Salamanca, narra sus experiencias sobre el espacio que habita y considera su hogar «Es una ciudad que crece, aunque lentamente: una ciudad que extiende su comercio, y aunque en menor escala, también su industria y su agricultura».

Diferente era la visión que nos ofrecía Federico García Lorca de otra capital de provincia, pero en este caso de Andalucía en un primer ejercicio literario en prosa: Impresiones y paisajes (1918), obra donde ya empezaba a apuntar «una idea de paisaje explícitamente formulada o trascendente» (Tort, 2007: 328). De su ciudad dijo, en su fantasía simbólica, que «el viento convierte en órgano a Granada, sirviéndole de tubos sus calles estrechas». El texto que recogemos se centra en una parte muy singular de la ciudad, desarrollando un juego entre lo construido y el viento circundante, mostrando la herencia del urbanismo islámico: «El Albaizín se amontona sobre la colina... Están las casas colocadas, como si un viento huracanado las hubiera arremolinado así. Se montan unas sobre otras con raros ritmos de líneas».

\section{De la postguerra a la democracia urbana}

Concluida la guerra civil comenzaron a redactarse los primeros planes de reconstrucción de grandes ciudades, así como el desarrollo de la legislación en favor de la vivienda, especialmente la «subvencionada» (1957), dirigida hacia los sectores populares y a la clase trabajadora, al tiempo que existió tolerancia 
ante el barraquismo. El texto de la Ley sobre Régimen del Suelo y Ordenación Urbana (1956) fue mejor que sus consecuencias, pues los sucesivos planes generales de ordenación urbana originaron: la destrucción del legado urbanístico, el abandono y deterioro de los centros históricos y la desorganización de las periferias, aspectos todos ellos que forzaron la aparición de las Asociaciones de Vecinos, como respuesta social de la población trabajadora e inmigrante que ocupaba las nuevas periferias. Con el texto refundido de la ley (1976) se inició el control democrático desde los ayuntamientos dando lugar a unos planes generales que querían terminar con la ciudad especulativa y de renovación, en definitiva un nuevo urbanismo más comprometido con el patrimonio, sin ocultar algunos desafueros. Un grupo de propietarios integrado por el capital inmobiliario y financiero controlará las principales inversiones y el mayor porcentaje del valor de cambio, quedando Madrid a la cabeza de la riqueza catastral urbana por asentarse allí los grandes capitales y una nómina muy amplia de nobleza titulada.

Para entender esta etapa elegiremos una novela sobre Madrid, la que nos parece más trascendental, para a continuación centrarnos en tres novelas sobre Barcelona. Luis Martín-Santos en Tiempo de silencio (1961), retrata el Madrid de 1949, en ella nos ofrece los estratos sociales de una ciudad a partir de un renovado estilo. El autor nos lleva a través de los barrios suburbiales hasta las chabolas, describiendo con detalle los materiales utilizados para su construcción como "oníricas construcciones», siendo las primeras autoedificaciones surgidas en los descampados de las entradas a la ciudad. Tres novelas claramente urbanas vienen a describir la realidad de Barcelona, la primera se centra en el casco histórico, la segunda en la zona más suburbana, y la tercera, nos evoca su pasado para demostrar que siempre ha apostado por la innovación. Nos estamos refiriendo, en primer lugar a Nada (1945) de Carmen Laforet, en la que se ofrece un retrato de la Barcelona vencida y ocupada en los años cuarenta, reflejando la sordidez y la mediocridad. Señala los distintos ambientes urbanos: La Vía Layetana «tan ancha, grande y nueva, cruzaba el corazón del barrio viejo»; luego la referencia a la catedral y al barrio gótico «naufragando entre húmedas casas construidas sin estilo en medio de sus venerables sillares»; y por último, las Rambas «conmovidas de animación y de luces». La segunda obra se desarrolla en la zona más periférica de la urbe, nos referimos a la novela-reportaje de Francisco Candel, Donde la ciudad cambia su nombre (1957). Narra su visión de los barrios planificados y espontáneos, ocupados todos ellos por charnegos, rodeados de fábricas y chimeneas: «Estas barracas se han reproducido y procreado como hongos... Estos barrios son, poco más o menos, como una perdigonada en una sábana». 
En la etapa democrática surge la tercera novela sobre Barcelona, en ella más que mirar a la ciudad del presente, gira hacia el pasado con el fin de prepararnos para un nuevo acontecimiento internacional, por este motivo se ha afirmado que marca la transición entre la modernidad y la posmodernidad, convirtiendo a Barcelona en tema y protagonista a la vez (Schwarzbürger, 2002). Lógicamente nos estamos refiriendo a Eduardo Mendoza y su novela La ciudad de los prodigios (1986), obra especialmente representativa, por su interés geográfico. Muestra una ciudad orgullosa de las dos Exposiciones Universales (1888 y 1929), y de su Ensanche, diseñado por Cerdá (1859): «El viajero que acude por primera vez a Barcelona advierte pronto dónde acaba la ciudad antigua y empieza la nueva», para además señalar que «De ser sinuosas las calles se vuelven rectas y más anchas... Era una cuadrícula indiferenciada que desconcertaba a forasteros y nativos por igual...». Se ha dicho de esta novela que es un dibujo neosocial que recoge los cambios sufridos, la deuda que registró en un periodo crucial de su historia, y también, su conversión en avanzadilla de España (Sebastián y Servén, 2011). En definitiva, la narración muestra su historia urbana, caracterizada por la industrialización y su expansión.

Un caso muy significativo en muchas ciudades españolas, fue que mientras las consideradas con escaso patrimonio construido fueron renovados en su totalidad sus centros, produciéndose procesos de retranqueamiento, y por tanto desapareciendo parcialmente la trama urbana y gran parte de sus principales edificaciones; por el contrario, las ciudades histórico-artísticas, algunas de ellas hoy Patrimonio de la Humanidad, el centro se abandonó, se envejeció, llevando a cabo todo el proceso constructivo a su periferia, perdiendo la ciudad vieja el sentido de ciudad viva. Rafael Chirles en El viajero sedentario. Ciudades (2004) hace referencia en su recopilatorio, de distintos viajes anteriores al nuevo siglo, a las ciudades-museo, a las ciudades sin vida propia, para afirmar que «el tiempo se detuvo para ellas y las envolvió con capacidad paralizante».

\section{LA CIUDAD EN LA ACTUAL POSMODERNIDAD}

La ciudad postindustrial o actual vino marcada por dos tendencias contrapuestas, por un lado la periurbanización, que dio lugar a la ciudad difusa o dispersa, recualificando la periferia; y por otra, la reurbanización o recentralización, lo que supuso una mayor preocupación por el espacio histórico, sin olvidar los grandes eventos del 92 y sus negativas consecuencias en el uso del suelo urbano. 
La ciudad dispersa se desbordó sobre el campo, más allá del continuo urbano, revitalizando pequeñas localidades y originando una alta dependencia del automóvil, utilizando como instrumento de expansión la vivienda unifamiliar, con sus problemas de insostenibilidad y de no ser útil en las edades avanzadas, pues llegado el momento las abandonan para volver al piso. Respecto a la recentralización, tendríamos que hacer mención a la revitalización de los centros a costa de acontecimientos o eventos, convirtiendo la ciudad en mercancía, en espectáculo; llevando también a cabo todo un proceso de rehabilitación, peatonalización, mejora del equipamiento urbano, con el fin de atraer población y visitantes. A estos dos aspectos operados en el centro y en la periferia se unieron las consecuencias de la Ley sobre Régimen del Suelo y Valoraciones (1998), principal responsable de la burbuja inmobiliaria, y de las leyes autonómicas de la Actividad Urbanística, que han otorgado supremacía al proyecto sobre el plan, lo que ha producido, todo ello, la crisis del urbanismo y de la vivienda. El principal obstáculo para el conocimiento de esta realidad la encontramos en la opacidad catastral, al omitir la referencia directa a los propietarios, y en la Ley Orgánica de Protección de Datos de Carácter Personal (1999), que ha frenado una tradición geográfica basada en considerar el estudio de la propiedad como elemento fundamental de las transformaciones operadas en el suelo urbano-rural.

Durante los años noventa la relación geografía urbana-literatura quedó claramente expresada en distintos estudios, y especialmente sobre Barcelona (Carreras, 1994, 1995) ciudad que ha sido ejemplo de claros procesos de maquillaje que han actuado sobre su espacio central o lo que se conoce como distrito quinto o «Barrio chino»y «el Raval» (Castellanos, 2002). En este interés por el espacio central, por un barrio significativo en la ciudad de Madrid, encontramos una novela de Julio Llamazares: El cielo de Madrid (2005) donde al referirse al «barrio viejo» de Chueca, señala las transformaciones experimentadas «entonces estaba lleno de viejas tiendas y tabernas... y ahora era el más divertido y concurrido de la ciudad... sus viejas callejas y plazoletas se convirtieron en una especie de laberinto», ejemplo actual del proceso de gentrificación urbana y de recentralización. Antes de pasar a las obras que han analizado la periferia, la ciudad difusa, tendremos en consideración la novela escrita por el nuevo Premio Príncipe de Asturias de las Letras, Antonio Muñoz Molina: Los misterios de Madrid (1992). El protagonista comenzará su extenso paseo por la ciudad, desde la estación de Atocha, detectando los principales cambios morfológicos: «ni siquiera encontraba el Scalextric»; luego recorrerá el centro histórico llegando hasta la Plaza Mayor, «el corazón del viejo Madrid», los barrios más castizos «la Ribera de Curtidores, arteria principal del 
populoso Rastro», para después centrarse en la Castellana «los modernos edificios de acero y vidrio se alternaban con señoriales palacetes estucados en blanco», la Fuente de Cibeles «la más monumental de Madrid», y por último, las barriadas más suburbanas, así como los barrios de chabolas «sobre los tejados de cartones y de chapas brillaba al sol un bosque metálico de antenas, algunas de ellas parabólicas», con un viario de "calles desiguales y polvorientas, trazadas al azar o al antojo...», todo ello muestra un recorrido real por el conjunto de la ciudad.

Una serie de novelas claramente posmodernas sobre Madrid se han caracterizado por centrar su atención en el fenómeno de la ciudad difusa, es decir, la expansión hacia las afueras de las construcciones urbanas, contraponiendo el centro con la no-ciudad, con la periferia y con las autopistas que unen los distintos fragmentos de ciudad, donde las imágenes de la ciudad vivida, imaginada y deseada se superponen (Tutoras, 2006), llevadas algunas de ellas al cine, aunque con escasa o nula descripción geográfica ${ }^{4}$.

Para finalizar recogeremos del poeta que se ha considerado como el más urbano de la poesía actual (Pillet, 2012b) sus versos más descriptivos, dedicados a las afueras de Madrid, nos referimos a Luis García Montero en su poema sobre la Barriada del Pilar: «ocho kilómetros / por una carretera con semáforos, / coches encadenados, impaciencia». En el recopilatorio de su poesía urbana (2010) a Madrid se unen Nueva York y su urbe natal Granada, y aunque en el prólogo Scarano hace mención a la «omnipresencia evidente de la ciudad», lo cierto es que en esta poesía de la existencia, realista y figurativa, hay más escenario o espacio vivido que descripción de ciudades, que «se hacen de hormigón y de cristal».

En el paso de un siglo a otro, destacaremos la contraposición entre las ciudades que se han mantenido a lo largo del tiempo y las que se han destruido urbanísticamente, pudiendo encontrar distintos ejemplos, para el primer caso citaremos a Sevilla y para el segundo a Alicante. La novela de Antonio Gala: Más allá del jardín (1995), nos presenta una urbe convertida en museo «preparada para los turistas», con todos los tópicos a respetar, por ejemplo, desde el barrio de Los Remedios «sólo se distinguían La Giralda, los remates de las torrecillas de la plaza de España...»; pero también la realidad suburbana donde aparecen los barrios de gitanos: «había chabolas inhabitables levantadas con

\footnotetext{
${ }^{4}$ José Ángel Mañas (Historias del Kronen, Mensaka, Ciudad Rayada y Sonko 95); Lucía Etxebarría (Amor, curiosidad, prozac y dudas; y Beatriz y los cuerpos celestes); y Jesús Ferrero (El diablo de los ojos).
} 
materiales de derribo». Respecto a la segunda ciudad que mencionábamos, encontramos una narrativa que tiene por objeto buscar el pasado, los restos de una ciudad, para poderla identificar. Nos estamos refiriendo a la obra de Mariano Sánchez Soler: Alacant blues. Crónica sentimental de una búsqueda (2002), en la que se menciona al viejo y noble Alicante «El Barrio había resistido todos los embates de los años difíciles», a continuación citaba al popular barrio de Santa Cruz «con sus calles estrechas, empinadas y olorosas de cal y geranios», para a continuación recordar lo ya desaparecido como consecuencia de la especulación; así como la escasa planificación seguida en las actuaciones surgidas desde los años sesenta: «a ritmo de inmigración y suelo barato crecía hacia todas las periferias, dejando espacios vacíos entre los nuevos barrios». Vaciamientos que se han ido cubriendo con el paso del tiempo y con la aparición del tranvía, nuevamente, como garante para seguir sellando la dispersión o fragmentación.

\section{NUEVA YORK: LA CIUDAD MODERNA Y LA CIUDAD ACTUAL}

El urbanismo del siglo xx fue una reacción a los males del siglo anterior, la metrópoli se había convertido en la primera del mundo con mayor número de inmigrantes, lo que originó un grave problema de viviendas, pues junto a su escasez, existían distintos aspectos que impedían su desarrollo: el valor del suelo, la poca higiene y el fuego, fue esto último lo que originó la aparición de escaleras de incendio en sus fachadas. Se dio una clara separación social por barrios, mientras las líneas del tranvía y el metro posibilitaron la aparición de nuevos barrios residenciales suburbanos, en los barrios pobres se hacinaba la población (Hall, 1996). La ciudad de los rascacielos se había convertido en un producto de consumo, soporte físico sometido a leyes de mercado, en el respeto sagrado a la propiedad privada, convertida Nueva York en "paradigma de ciudad como soporte de producción». La nueva metrópolis americana desvela así una ciudad moderna que permitiría destruirse y reinventarse de nuevo cada día, dejando para el presente una nómina escasa de edificios singulares del pasado (Loren, 2007).

El motivo de traer a estas páginas la presencia de Nueva York se debe, como ya hemos afirmado, a que esta ciudad ha sido la que más ha interesado a los escritores españoles a lo largo del siglo pasado, pues vino a sustituir a París como capital del mundo, y se convirtió en la que mejor ostentaba la idea de modernidad, al mismo tiempo que la ciudad iba transformando su fisonomía de forma extraordinaria, viendo como los rascacielos se sucedían compitiendo 
en altura y en armonía constructiva. Una obra ha venido a analizar la amplia relación de poetas que siguieron el ejemplo que inició Juan Ramón Jiménez, utilizando la mayor parte de ellos hasta la actualidad, la ciudad como escenario, con escasas referencias: la geometría de su urbanismo, los rascacielos, los cementerios, etc.; siendo la mayor parte de ellos profesores ${ }^{5}$, que se instalaron en la ciudad por unos años o la visitaron (Neira, 2012). Junto a estas aportaciones presentaremos las obras que nos parecen más significativas por la descripción de la ciudad.

En las primeras décadas del pasado siglo, cuando la transformación urbana aún no era muy patente, Juan Ramón Jiménez en su obra Diario de un poeta recién casado (1916), escrita en verso y prosa poética, indica por un lado, su admiración ante la metrópoli: « ¡New York, maravillosa New York!», ciudad que le sorprende por el movimiento de la urbe, por los distintos medios de locomoción; pero también descubre su lado más oscuro: llena de malos olores, que es donde malviven personas de distintas razas «aquí viven -chinos, irlandeses, judíos, negros-». Mayor interés tuvo la aportación de José Moreno Villa en Pruebas de Nueva-York (1927) donde describe una visión muy acertada sobre la ciudad más espectacular del momento, con el mayor espíritu de justicia que puede. Presenta un urbanismo de amontonamiento, de casas apiñadas y altas: «un montón de cajones monstruosos», situación que razona debido al poco espacio existente, lo que obliga a tener que aprovechar al máximo el suelo "ganando espacio en el espacio aéreo», lo que da origen a «casas gigantescas a la vez que estrechas». Hace hincapié en un fenómeno que llama la atención a los visitantes de la ciudad como es el caso de las escaleras de incendios en las fachadas, a la vez que menciona el proceso de destrucción-construcción de inmuebles, donde queda claro cómo se han ido sucediendo los elevados bloques de viviendas y cómo grandes edificaciones han dado paso a nuevas torres: «La construcción que tenga veinticinco años se mira con recelo y se la señala enarbolando imaginaria piqueta», aclaración que nos ayuda a comprender el proceso de rápida renovación llevada a cabo en aquellos años. De su aportación ha indicado Cañas (1994) que ofreció interesantes descripciones sin perder de vista ningún aspecto de la vida urbana y social.

La crisis del 29 y la del 73 marcaron la vida de esta ciudad, la primera la vivió directamente Federico García Lorca, tal y como lo desvela en su poemario Poeta en Nueva York (1930), y en la correspondencia que mantuvo, así como

\footnotetext{
${ }^{5}$ Distintos poetas utilizaron la ciudad como escenario, los mejores ejemplos fueron: R. Alberti, P. Salinas, J. Guillén y L. Cernuda; más recientemente cabe destacar las obras de José María de Fonollosa: Ciudad del hombre: New York (1990) y Dionisio Cañas: Lugar (2010).
} 
en sus posteriores conferencias (Barrantes, 2007 y Villanueva, 2008). El poeta reconoce la sorpresa que le produjo la ciudad «New York me ha dado como un mazazo en la cabeza». En su poema New York denuncia un mundo urbano en dos mitades diferentes: "Yo denuncio a toda la gente / que ignora la otra mitad, / la mitad irredimible / que levanta sus montes de cemento», o bien su poema La Aurora donde muestra una obra más expresionista que surrealista: «Por los barrios hay gentes que vacilan insomnes/ como recién salidos de un naufragio de sangre». Lorca contrapone dos aspectos diferentes: modernidad y progreso, así como dos tipos de paisajes urbanos: el antiguo de las ciudades de Europa y el frenético de Nueva York: «la ciudad más atrevida y más moderna del mundo» (Jaén, 1993). Una aportación interesante es también la del periodista Julio Camba en su recopilatorio: La ciudad automática (1934) donde tras afirmar que «Nueva York es una ciudad que me irrita, pero que me atrae de un modo irresistible», analizará las características de dos barrios (Harlem y Judío) para luego centrarse en unos de los aspectos que más le llamó la atención: los rascacielos. Tras señalar que ha posibilitado su enorme ensanche gracias a los puentes y túneles, indicará que estas elevadísimas edificaciones «no son una consecuencia del excesivo precio de sus solares, sino que, al contrario, el excesivo precio de sus solares es una consecuencia directa de sus rascacielos», al tiempo que se ha convertido en su arquitectura propia, la que define a su ciudad; es decir, todo lo contrario a la homogeneidad que caracteriza a París.

Un espectador de la crisis del 73 y de la dimisión del presidente Nixon (1974) fue Eduardo Mendoza tal y como nos lo desvela en su narrativa sobre Nueva York (1986) en la que refleja los recuerdos de su estancia. El autor une dos aspectos, por un lado la considera la ciudad de moda, con su «fachada marítima teatral» pero también la que está sufriendo, en primera persona, las consecuencias de la crisis y la bancarrota, pues el desanimo impregna la vida urbana: Nueva York se muestra como una ciudad vieja basada en la empresa mediana y pequeña, la iluminación pública es escasa, las calles, llenas de vagabundos, más los problemas de higiene (ratas y cucarachas). La oferta de pisos supera la demanda, siendo más elevado el alquiler conforme es mayor la altura.

\section{La ciudad global entre un siglo y otro}

Si hacemos referencia a las últimas décadas, la ciudad se convierte en centro de atención al ser considerada la primera ciudad global del mundo según se manifestaba en la obra de Saskia Sassen (1991) donde se le atribuye «haber 
alcanzado los límites de la centralización de funciones». Esta metrópoli ha sido ejemplo de una intensa urbanización de la periferia a partir de viviendas unifamiliares que se convierten en el elemento central de su estructura urbana. La actual ciudad postindustrial está originando: la desindustrialización y terciarización, la mayor integración en la economía global, la reestructuración de la forma urbana y el aumento de las desigualdades, la segregación social y espacial, así como la privatización del espacio urbano y la fragmentación de la forma urbana, siendo Manhattan el centro de una economía de aglomeración según indicaba Pacione en su obra publicada en Nueva York (2001).

Finalizando los noventa, el poeta José Hierro con Cuaderno de Nueva York (1998), continuará recogiendo los viejos temas que llamaron la atención a todos los que viajaron a la ciudad durante el siglo: los anuncios luminosos, y los «rascacielos de acero y miel». Rapsodia en Blue será el poema de más interés geográfico: «La geometría de New York se arruga, / se reblandece como una medusa / se curva, oscila, asciende, lo mismo que un tornado / vertiginosa y salomónica». Un autor del que hemos recogido su aportación sobre Madrid, aparece nuevamente ahora en la que ha sido su segunda residencia, nos referimos a Antonio Muñoz Molina, con una obra de vivencias: Ventanas de Manhattan (2004). Se inicia con los recuerdos de sus primeros viajes «a principios de los noventa, Manhattan tenía una población de pobres errantes que fueron desapareciendo... Estaban en todas las esquinas...». En segundo lugar, una constante que marcó el nuevo siglo en lo que se ha denominado como Zona Cero: «Las torres ardiendo, derrumbándose como torpes maquetas». Luego aquellos aspectos que se perciben cuando se visita esta ciudad: que existe poca iluminación pública, tan sólo la luz de la publicidad y los escaparates; que es una gran maquinaria, y el «gran bazar del mundo». Para añadir que este espacio construido se sustenta sobre débiles cimientos: el «subsuelo, en realidad es tan frágil como un castillo de arena o de naipes»; dando como resultado una morfología urbana "permanentemente construida y destruida», lo que ha originado que «en el último siglo el paisaje de Manhattan se ha modificado radicalmente». Por su parte, Enric González en su obra periodística Historias de Nueva York (2006) nos da cuenta de los edificios que se salvaron de la demolición. Se detiene en las presiones de unos barrios sobre otros, como es el caso de que la Pequeña Italia desapareciera hace tiempo devorada por su vecina Chinatown. Respecto al uso del suelo y su relación con los rascacielos se afirma que «En Nueva York, una cosa es la propiedad del suelo y otra la propiedad del aire, y muchas veces pertenecen a gente distinta». Para a continuación añadir que «El aire, es decir, el derecho de edificación sobre un solar a partir de cierta altura, puede ser tan caro o más que la tierra». Como vemos, la 


\section{FIGURA 1}

RASCACIELOS DEL SUR DE MANHATTAN

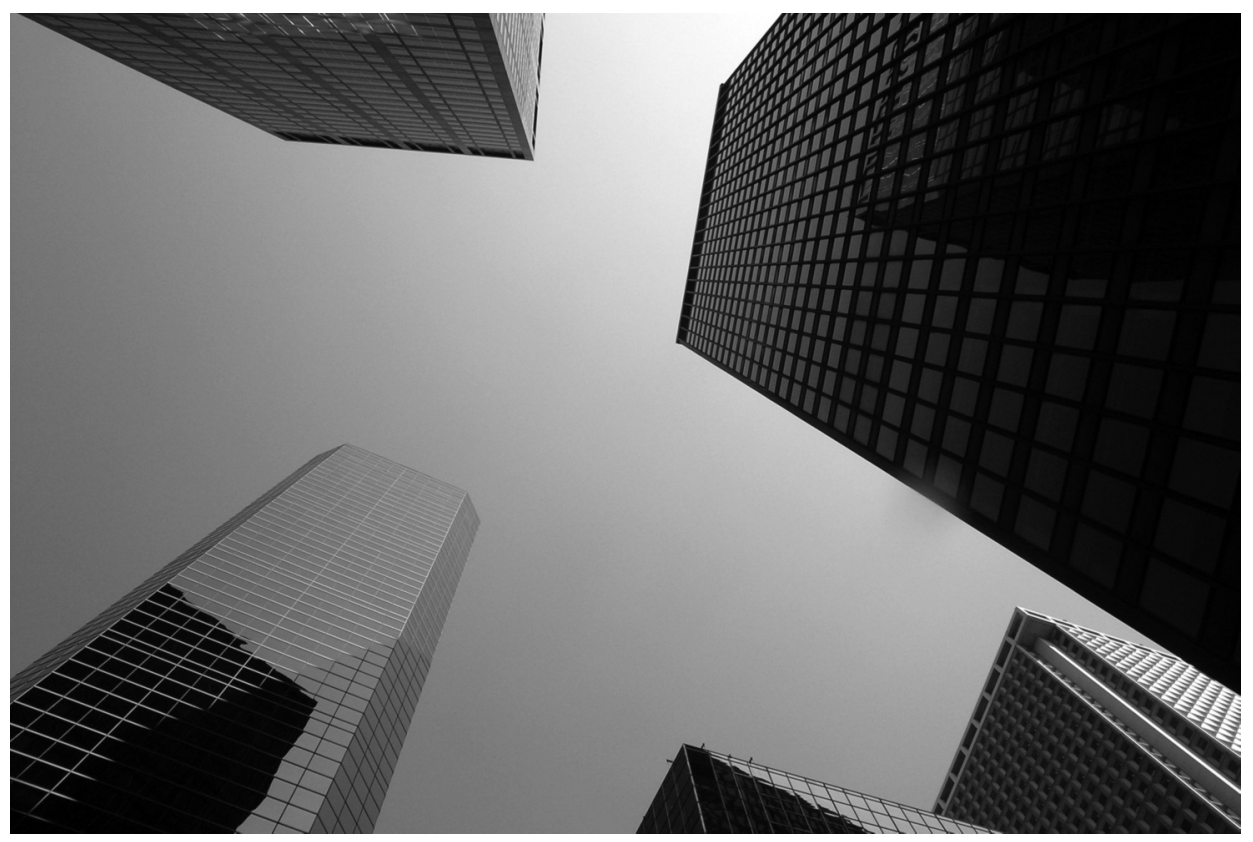

F. Pillet (2008).

referencia al precio del escaso suelo y su relación con la construcción en altura, son siempre una constante, una realidad que sorprende al viandante cuando comprueba que en las esquinas de la gran manzana, apenas queda espacio para contemplar el cielo (figura 1).

\section{Conclusión}

La literatura nos ha ofrecido innumerables obras que han tenido como fondo o escenario la ciudad, pero ha sido preciso, tras una lectura amplia, seleccionar aquellas que han descrito, sin querer ser exhaustivos, la trama urbana de algunas ciudades españolas, especialmente Madrid, pero también otras que se suceden a lo largo del texto: Oviedo, Cuenca, Segovia, Salamanca, Granada, Barcelona, Sevilla y Alicante; a las que se ha unido una gran metró- 
poli: Nueva York, por ser la que más ha despertado la atención de nuestros escritores españoles en legua castellana, desde comienzos del siglo pasado. Como resultado del trabajo llevado a cabo, se desprende, nuevamente, la utilidad de la fuente literaria para el conocimiento del devenir urbano, del proceso de urbanización y muy especialmente la evolución de la ciudad moderna a la actual posmodernidad, para así comprender mejor las modificaciones que fueron sufriendo los espacios urbanos, desde la mirada y la imagen literaria, desde la visión subjetiva. La relación literatura-paisaje y más concretamente literatura-ciudad no solo convierte al texto literario en una fuente de investigación para la comprensión del hecho urbano, como resultado de las emociones despertadas por el viajero; sino que además en la actual sociedad del ocio, esta relación viene a aportar a los turistas un documento, una guía de viaje fundamental para el desarrollo del turismo cultural (Pillet, 2014).

Durante el siglo XIX hemos comprobado en las ciudades españolas la situación llevada a cabo antes y después del derribo de las murallas y la llegada del ferrocarril, es decir el relleno interno de la trama urbana en un primer momento, para a continuación centrarnos en los nuevos ensanches. En el siglo xx la ciudad de Nueva York se convierte en el gran modelo a seguir, con un desarrollo concentrado apoyado en las construcciones de grandes alturas o rascacielos, para en las últimas décadas producirse la ciudad dispersa. En el pasado siglo aparecen una serie de escritores españoles en lengua castellana que se han interesado tanto por una ciudad española como por la gran metrópoli mundial, ofreciendo textos literarios descriptivos, siendo los mejores ejemplos: en las primeras décadas, Juan Ramón Jiménez y Federico García Lorca; y en las últimas, de manera muy clara, Eduardo Mendoza y Antonio Muñoz Molina.

Fecha de recepción: 3 de abril de 2014.

Fecha de aceptación: 9 de octubre de 2014.

\section{BIBLIOGRAFÍA}

Alas "Clarín", L. (1967): La Regenta. Barcelona, Planeta.

Arroyo Ilera, F. (1989): "El factor geográfico en «el problema de España»". Estudios Geográficos, L/196, pp. 333-368.

Arroyo Ilera, F. (2008): "Geografía, literatura e ideología en la segunda mitad del siglo xx: las Guías de España de Ediciones Destino”. Estudios Geográficos, LXIX/265, pp. 417-452. 
Baroja, P. (1934): Caminos de perfección. Madrid, Espasa-Calpe.

Baroja, P. (1937): Los recursos de la astucia. Madrid, Espasa-Calpe.

Baroja, P. (1969): La Busca. Madrid, Salvat-Libros RTV.

Barrantes Martín, B. (2007): Ciudad y modernidad en la prosa hispánica de vanguardia. Valladolid. Universidad de Valladolid.

Camba, J. (2002): La ciudad automática. Madrid, Espasa-Calpe.

Candel, F. (1957): Donde la ciudad cambia su nombre. Barcelona, José Janés editor.

Cañas, D. (1994): El poeta y la ciudad. Nueva York y los escritores hispanos. Madrid, Cátedra.

Cañas, D. (2020): Lugar. Madrid, Hiperión.

Capel, H. (2001): Dibujar el mundo. Borges, la ciudad y la geografía del siglo XXI. Barcelona, Ediciones del Serbal.

Carreras i Verdaguer, C. (1994): "La ciudad de la postmodernidad. Una aproximación geográfica a través de la Literatura”, en: Actas del I Coloquio internacional literatura y espacio urbano. Alicante, Caja de Ahorros del Mediterráneo, pp. 132-142.

Carreras i Verdaguer, C. (1995): "La ciudad de Barcelona en la literatura catalana". Anales de Geografía de la Universidad Complutense, 15, pp. 221-233.

Carrión, J. (2009): Madrid/Barcelona. Literatura y ciudad (1995-2010). Madrid, Iberoamericana Editorial Vervuert.

Castellanos, J. (2002): "Barcelona, las tres caras del espejo: del Barrio Chino al Raval". Revista de Filología Románica, III, pp. 189-202.

Cela, C. J. (1970): La colmena. Madrid, Alfaguara.

Chirbes, R. (2004): El viajero sedentario. Ciudades. Barcelona, Anagrama.

Edd Benaiges, M. J. (2005): "Dones i ciutat a la Barcelona del segle XX: Una anàlisi geográfica a través de la literatura”. Universidad Autónoma de Barcelona (Tesis doctoral), disponible en http://www.tdx.cat/handle/10803/4961 (Verificada el 14/04/2015).

Espejo Marín, C. y López de los Mozos González, M. A. (2012): "El paisaje de Madrid en la obra de Antonio López García”. Nimbus, 29-30, pp. 217-232.

Fonollosa, J. M. (1990): Ciudad del Hombre: New York. Barcelona, Sirmio.

Gala, A. (1998): Más allá del jardín. Barcelona, Planeta.

García Jambrina, L. (2006): "Literatura y ciudad". Clarín, 64, pp. 53-54.

García Lorca, F. (1972): Poeta en Nueva York. Barcelona, Ocnos.

García Lorca, F. (1994): Impresiones y paisajes. Madrid, Cátedra.

García Montero, L. (2010): Poesía urbana: Antología 1980-2010. Sevilla, Renacimiento. Gómez de la Serna, R. (1931): El Rastro. Madrid, La Nave.

González, E. (2006): Historias de Nueva York. Barcelona, RBA.

Hall, P. (1996): Ciudades del mañana. Historia del urbanismo en el siglo XX. Barcelona, Ediciones del Serbal.

Hierro, J. (1998): Cuaderno de Nueva York. Madrid, Hiperión.

Jaén i Urban, G. (1993): "El paisatge urbà de Nova York em l'obra de Federico García Lorca". Canelobre, 25/26, pp. 1-24. 
Jiménez, J. R. (1971): La colina de los chopos. Madrid posible e imposible. Madrid, Taurus. Jiménez, J. R. (1972): Libros de poesía. Madrid, Aguilar.

Laforet, C. (1946): Nada. Barcelona, Destino.

Langa Laorga, M. A. (1994): "Literatura y sociedad: la ciudad levítica, modelo sociológico en evolución”. Cuadernos de Historia Contemporánea, 16, pp. 167-182.

Larra, M. J. (1971): Artículos de costumbres. Madrid, Espasa-Calpe.

Lévy, B. (2006): "Geografía y literatura", en D. Hiernaux y A. Lindón (dirs.): Tratado de Geografía Humana. Barcelona, Anthropos, pp. 460-480.

Loren, M. (2007): "La ciudad de Nueva York y la crisis del paradigma urbano". Formas de Arquitectura y Arte, 16, pp. 13-21.

Lois González, R. C. (coord.) (2012): Los espacios urbanos. El estudio geográfico de la ciudad y la urbanización. Madrid, Biblioteca Nueva.

Llamazares, J. (2005): El cielo de Madrid. Barcelona, Círculo de Lectores.

López Cabrales, J. J. (2000): "La ciudad de las palabras. Imágenes urbanas en novelas españolas contemporáneas". Universidad de Cádiz, (Tesis doctoral, CD).

López Ontiveros, A. (2006): "Literatura, Geografía y representación del paisaje", en A. López Ontiveros y N. Ortega Cantero (Coords) Representaciones culturales del paisaje y una excursión por Doñana. Madrid, Universidad Autónoma de Madrid, pp. 13-40.

Lozano Marco, M. A. (1994): "Una visión simbolista del espacio urbano: la ciudad muerta", en J. C. Rovira y J. R. Navarro: Literatura y espacio urbano. Alicante, Caja de Ahorros del Mediterráneo, pp. 60-73.

Maderuelo, J. (2010): "El paisaje urbano". Estudios Geográficos, 269, pp. 575-600.

Martínez de Pisón, E. (2009): Miradas sobre el paisaje. Madrid, Biblioteca Nueva.

Martínez Ruiz “Azorín”, J. (1968): La voluntad. Madrid, Castalia.

Martínez Ruiz “Azorín”, J. (1975): Doña Inés: (historia de amor). Madrid, Castalia.

Martín-Santos, L. (1971): Tiempo de silencio. Madrid, Seix Barral.

Mcdonogh, G. W. (1988): "Ciudades de mujeres: literatura, poder y situación en Barcelona a principios del siglo xx". Estudios Geográficos, XLIX/191, pp. 189-208.

Mendoza, E. (1986): La ciudad de los prodigios. Barcelona, Seix Barral.

Mendoza, E. (1986): Nueva York. Barcelona, Ediciones Destino.

Mesoneros Romanos, R. de (1846): Escenas matritenses. Valparaiso, Tornero y Benítez.

Moral, R. del (1992): "Madrid como escenario literario en la novela española contemporánea". Universidad Complutense de Madrid (tesis doctoral), disponible en: http://es.scribd.com/doc/25124729/MADRID-EN-LA-NOVELA-1939-1975 (Verificada el 14/04/2015).

Moreno Villa, J. (1927): Pruebas de Nueva-York. Málaga, Imprenta Sur.

Muñoz, M. (2010): "Las ciudades invivibles. Una visión novelada de la experiencia urbana moderna". Revista Nodo: Arquitectura, Ciudad y Medio Ambiente, 8, pp. 59-72.

Muñoz, M. (2012): "La ciudad moderna, literalmente hablando. O cómo leer lo que dicen los escritores de ficción sobre los asentamientos". Revista de Arquitectura, 14, pp. 12-19.

Muñoz Molina, A. (2006): Ventanas de Manhattan. Barcelona, Seix Barral 
Muñoz Molina, A. (2013): Los misterios de Madrid. Barcelona, Seix Barral

Neira, J. (2012): Historia poética de Nueva York en la España contemporánea. Madrid, Cátedra.

Ortega Cantero, N. (2007): "Lectura geográfica del paisajismo literario de la generación del 98", en V. Paül y J. Tort (eds.): Territorios, paisajes y lugares. Cabrera del Mar, Galerada y Asociación de Geógrafos Españoles, pp. 281-297.

Ortega Cantero, N. (2010): "La conformación de un paisaje nacional: Castilla (18761936)", en N. Ortega, J. García y M. Mollá (eds.): Lenguajes y visiones del paisaje y del territorio. Madrid, Universidad Autónoma de Madrid, pp. 45-53.

Pacione, M. (2001): Urban geography: a global perspective. New York, Routledge.

Pérez Galdós, B. (1975): Fortunata y Jacinta. Dos historias de casadas. Madrid, Editorial Hernando.

Pérez Galdós, B. (1982): Misericordia. Madrid, Cátedra.

Pérez Pérez, Ma C. (2006): "La representación realista del espacio. De Madame Bovary a La Regenta", en M. Bruña et al., (coords.): La cultura del otro: español en Francia, francés en España. Sevilla, Universidad de Sevilla, (CD ROM), pp. 605-615.

Pillet Capdepón, F. (2012a): Planificación territorial. Propiedad y valoración catastral (España 1750-2010). Madrid, Biblioteca Nueva.

Pillet Capdepón, F. (2012b): "El paisaje de España en sus versos: de la naturaleza a la ciudad". Nimbus, 29-30, pp. 531-547.

Pillet Capdepón, F. (2014): "El paisaje literario y su relación con el turismo cultural". Cuadernos de Turismo, 33, pp. 297-309.

Rozas, J. L. (1996): "Poesía y Modernidad: Juan Ramón en las ciudades". Anuario de Estudios Filológicos, XIX, pp. 457-474.

Sánchez Soler, M. (2002): Alacant blues. Crónica sentimental de una búsqueda. Alicante, Agua Clara/Instituto Alicantino de Cultura "Juan Gil-Albert".

Schwarzbürger, S. (2002): "La ciudad narrada. Barcelona en las novelas urbanas de Eduardo Mendoza. La relación entre texto y ciudad". Revista de Filología Románica, III, pp. 203-220.

Sassen, S. (1999): La ciudad global. Nueva York, Londres y Tokio. Buenos Aires, Eudeba.

Sebastián, A. y Servén, C. (2011): "Urbanismo y literatura en La ciudad de los prodigios". Inventio, 13, pp. 99-105.

Sierra, J. C. (2006): El Madrid de Larra. Madrid, Silex.

Sturm-Trigonakis, E. (1996): Barcelona: la novel-la urbana (1944-1988). Kassel, Edition Reichenberger.

Tudoras, L. E. (2004): "La configuración de la imagen de la gran ciudad en la literatura postmoderna: (ámbito romántico)". Universidad Complutense de Madrid (Tesis doctoral), disponible en: http://biblioteca.ucm.es/tesis/fll/ucm-t27819.pdf. (Verificada el 14/04/2015).

Tudoras, L. E. (2006): "Propuesta para una lectura postmoderna de la ciudad". Cuadernos de Filología Italiana, 3, pp. 129-141.

Unamuno, M. (1975): Andanzas y visiones españolas. Madrid, Espasa-Calpe. 
Villanueva, D. (2008): Imágenes de la ciudad. Poesía y cine, de Whitman a Lorca. Valladolid, Cátedra Miguel Delibes.

Zárate Martín, M. A. (2010): "Paisajes culturales urbanos, un legado para conservar". Anales de Geografía, 30/2, pp. 187-210.

\section{RESUMEN}

El proceso de urbanización de la ciudad, dividido tradicionalmente en tres etapas (ciudad preindustrial, industrial y postindustrial o actual), lo hemos sintetizado en dos grandes momentos: la ciudad moderna (fase industrial) y la ciudad en la actual posmodernidad (fase postindustrial). La novedad de este trabajo consiste en analizar el proceso de urbanización tomando como referencia aquellas obras literarias, que hayan descrito la morfología urbana. Para este objetivo se ha tenido en cuenta la literatura española en lengua castellana desde comienzos del siglo XIX hasta la actualidad que hiciera referencia a las principales ciudades españolas, que son las siguientes, tal y como han ido apareciendo en el estudio: Oviedo, Madrid, Cuenca, Segovia, Salamanca, Granada, Barcelona, Sevilla y Alicante; junto a la que ha sido la gran metrópoli desde comienzos del siglo pasado: Nueva York, por ser la que más ha interesado a nuestros escritores.

PAlabras Clave: Imagen literaria; ciudad moderna; ciudad actual; posmodernidad; España; Nueva York.

\section{ABSTRACT}

Traditionally divided into three stages (pre-industrial, industrial and post-industrial), we have summarised the process of urban development into two key moments: the modern city (industrial stage) and the present-day, post-modern city (post-industrial stage). This new approach consists in analysing the process of urban development using various literary works that describe urban morphology as key points of reference. With this aim in mind, we have focused on Spanish (Castilian) literature from the beginning of the 19th century to present day that refers to the main Spanish cities, being, and appearing in the following order in this study: Oviedo, Madrid, Cuenca, Segovia, Salamanca, Granada, Barcelona, Sevilla and Alicante. These cities are analysed alongside New York, which has been the grand metropolis since the beginning of the previous century and is the city to have captured the imagination of our writers like no other.

KEY WORDS: Literary image, modern city, present-day city, post-modernity, Spain, New York.

\section{RÉSUMÉ}

Nous avons synthétisé le processus d'urbanisation de la ville, traditionnellement divisé en trois étapes (ville préindustrielle, industrielle et postindustrielle ou actuelle), 
en deux grandes périodes : la ville moderne (phase industrielle) et la ville dans le postmodernisme actuel (phase postindustrielle). La nouveauté de ce travail consiste à analyser le processus d'urbanisation en prenant comme points de référence ces œuvres littéraires qui ont décrit la morphologie urbaine. Pour ce faire, nous avons pris en compte la littérature espagnole écrite en castillan depuis le début du XIX ${ }^{e}$ siècle jusqu'à aujourd'hui faisant référence aux principales villes espagnoles suivantes, telles qu'elles apparaissent à tour de rôle dans l'étude : Oviedo, Madrid, Cuenca, Segovia, Salamanca, Granada, Barcelona, Sevilla et Alicante; en plus de celle qui est devenue la plus grande métropole à partir du début du siècle dernier : New York, dans la mesure où elle est celle qui a le plus intéressé nos auteurs.

Mots CLES: Image littéraire, ville moderne, ville actuelle, postmodernisme, Espagne, New York. 